\title{
Role conflict and Changing Heritage Practice: ancestral tourism in Scotland
}

Samantha Murdy, Matthew Alexander and Derek Bryce

Department of Marketing, Strathclyde Business School, University of Strathclyde, Glasgow, UK

Contact: Samantha Murdy; samantha.murdy@strath.ac.uk

\begin{abstract}
Developing mutually beneficial outcomes in service encounters can be challenging due to resource asymmetry within co-created experiences. Such encounters can result in role conflict for service providers. Limited attention has been paid to the effect on service providers of highly collaborative exchanges which require specific customisation. An example of this is ancestral tourism, a dimension of heritage consumption, in which visitors actively participate in the co-creation of experience at museums, archives and related heritage sites. These institutions, previously seen as repositories of historical information, now act as conduits for visitors to investigate their ancestral past. The purpose of this study is to explore the relationship between changing professional discourse in the cultural heritage sector, specifically ancestral tourism, and role conflict amongst staff. Through interviews conducted with professionals, the extent and outcomes of role conflict in complex and collaborative exchanges is explored.
\end{abstract}

\section{Keywords}

Role conflict, heritage tourism, ancestral tourism, Scotland 


\section{Introduction}

Mirroring developments in the wider service industry, heritage tourism encounters are increasingly focussed around individual demands for bespoke, personal experience based on a strong sense of subjective engagement with a destination's culture (Poria, Butler, \& Airey, 2003; Timothy \& Boyd, 2006). However, there has been little exploration in the heritage marketing and tourism literatures of consumer-practitioner interactions centred on the delivery of intangible experiences. Research on power relations between consumers and marketers, as well as between consumer groups and between firms, is vital in advancing the study of markets (Peñaloza \& Venkatesh, 2006). Prior research on role conflict suggests that tensions may develop between intra-organisational demands where employees are uncertain about personal autonomy in decision making, what they are expected to accomplish and how they may be judged when unscripted interactions with consumers occur (Bettencourt \& Gwinner, 1996).

Our paper explores the individual demands which stem from consumers' desire to understand more about their own personal history. Ancestral tourism is a phenomenon driven by tourists who are pulled 'home' by a sense of strong attachment to a destination previously resided in by their ancestors (Basu, 2004). Ancestral tourism is an increasingly important phenomenon in Scotland where, in the last 250 or so years, significant proportions of the population have emigrated in comparison to other European countries (Devine, 2011). Identified as a key area of growth by Scotland's national tourism organisation, ancestral tourism boasts an estimated market of 50 million people within the Scottish Diaspora in markets such as Canada, the USA, Australia, and New Zealand (Visit Scotland, 2013). This phenomenon has led to a change in the way heritage tourism is delivered to visitors, with a push for an increased focus 
on individualised experiences (see for example Poria, Butler, \& Airey, 2003; Timothy \& Boyd, 2006).

Research in the overlapping heritage marketing and heritage tourism literatures indicates that the sector continues to face external challenges to move away from being a solely top-down informed repository of legitimated, 'official' national, regional, cultural or religious identities and towards more responsive relationships with citizens as individual consumers (Guttentag, 2010; Kirshenblatt-Gimblett, 1998; Wight \& Lennon, 2007). This has the potential to create tensions amongst professionals in the sector who, understandably, feel a primary responsibility to the integrity and academically informed interpretation of the objects, documents, buildings and landscapes in their care, while working under utilitarian demands to commercialise experiences for consumer reception (Apsotolakis, 2003; Garrod \& Fyall, 2000). It is important to understand challenges faced by providers, given the increased attention paid to ancestral tourism within the Scottish tourism industry and, potentially, in other destinations with sizable overseas diasporas, including Ireland, China, Italy and India. As such, given the greater individualised nature of the service, the aim of this paper is to explore instances of role conflict as perceived by providers of ancestral tourism within Scotland and the strategies adopted to ameliorate any negative outcomes from encounters.

This paper contextualises these issues within the domain of cultural heritage experiences produced for the ancestral tourism market in Scotland in which consumer demands and roleconflict issues are particularly heightened. As our research will show, ancestral tourism provides an interesting context given the highly engaged nature of visitors. Types of role conflict are identified, across varying levels usually associated with resource asymmetry. We argue that while role conflict may occur, given the flattened nature of the relationship 
between consumer and professional staff, negative outcomes, as outlined in much of the extant literature, need not be assumed. That is, with the evident demands for participatory modes of consumption amongst ancestral tourists, such interactions with professional staff can become far more meaningful and beneficial.

\section{Literature Review}

Recent developments in Marketing, such as Service-Dominant Logic (Lusch \& Vargo, 2014; Vargo \& Lusch, 2015) and Customer Dominant Logic (Heinonen, Strandvik, Mickelsson, Edvardsson, Sundström, \& Andersson, 2010), are associated with and support the notion that service provision is undertaken mutually between consumer and provider through concepts such as co-creation or customer engagement (see Jaakkola \& Alexander, 2014). However, Edvardsson, Tronvoll, and Gruber (2011) suggest that the benefits that these collaborations can bring may not necessarily be shared equally between actors. In fact the likely outcome is often a "compromise between what the customer wants, the company wants and what the institutionalized reality allows" (Edvardsson et al., 2011, p. 335). The notion of compromise between actors is further complicated by the potential for actors to behave opportunistically when the information in encounters is distributed asymmetrically (Akerlof, 1970; Williamson, 1973). Increasing levels of collaboration in service encounters, the need for compromise, and the ongoing potential for asymmetric behaviour by parties have resulted in calls for research to explore consumer "subjective understandings and agenic practices regarding their participation in the co-creation of meaning and value, and consider who benefits from it" (Peñaloza \& Venkatesh, 2006, p. 307). Additionally Edvardsson et al. (2011, p. 335) suggest that concepts such as role conflict and role ambiguity should be considered within this framework of greater collaboration as personnel may be faced with "situations in which it is difficult to facilitate a mutually beneficial service exchange, because 
specific customer demands (for example, a desire for specific customization) contradict the company's rules and regulations".

\section{Role Conflict and Ambiguity}

The concepts of role conflict and ambiguity emerged in the late 1960s/70s (see House \& Rizzo, 1972; Katz \& Kahn, 1978; Rizzo, House, \& Lirtzman, 1970) and were concerned with so called violations of two classic organisational principles: 'unity of command' and 'single accountability'. With regard to the former principle, employees were traditionally seen as operating within a chain of command with authority flowing from the top to the bottom (Rizzo et al., 1970). Unity of command centres on the need for employees to receive 'orders' from one superior only, thus preventing employees "from being caught in the crossfire of incompatible orders or incompatible expectations from more than one superior" (Rizzo et al., 1970, p. 150). Single accountability states that an individual should be responsible for the execution of a task to one superior only. This principle aims to ensure consistency of reporting and evaluation within an organization. Rizzo et al. (1970) suggest that an inability to meet one or both principles leaves an employee open to role conflict.

Role conflict, therefore, occurs when an individual is faced with a situation where the expectations and demands given to them by other role senders (usually customer and organisation) (Shamir, 1980) are incompatible and violate one or both of the principles above (Bettencourt \& Gwinner, 1996). Role ambiguity is concerned with a lack of clarity over an individual's role and predictability of the outcomes of an employee's behaviour. Both behaviours are seen to impinge on job performance. 
Early research into the service domain suggested that front line (subordinate) service roles were more likely to experience role conflict (Schneider \& Bowen, 1985; Shamir, 1980). This was due to the "combination of expectation and pressure which is directed to the role occupant from both outside and within the organisation [creating] a conflict of interest as manipulating expectations and pressures from outside the organisation are more difficult to control" (Shamir, 1980, p. 742).

Extant literature reports a number of potential outcomes for employees experiencing either role conflict or ambiguity. Role stress, seen as a common outcome and a direct result of both conflict and ambiguity, is associated with reduced satisfaction in the workplace (Boles, Wood, \& Johnson, 2003) and contributes to performance issues and the loss of organisational efficiency and effectiveness (Rizzo et al., 1970; Shamir, 1980). Other negative outcomes of role conflict are related to stress and include: burnout (Edvardsson et al., 2011); reduced trust/liking for the persons imposing the conflict (Rizzo et al., 1970) and; ultimately psychological or behavioural withdrawal from the job or organisation altogether (Bettencourt \& Gwinner, 1996).

Other studies have presented outcomes which, although associated with increased levels of stress, result in improved job performance. For example, Onyemah (2008) reports that salespeople can experience functional benefits from role conflict which can spur performance. However, these benefits are temporal and revert to being dysfunctional in time (Onyemah, 2008). Likewise, Tang and Chang (2010) report that role conflict and ambiguity can have a positive and direct impact on employee creativity as conflicting job demands trigger innovative responses. The authors suggest that role conflict forces individuals "to 
become receptive to different viewpoints, be more flexible, and expand their source of information" (Tang \& Chang, 2010, p. 876).

In most cases reported in the literature, role conflict in service delivery is caused by an organisation or a customer exerting pressure to change the behaviour of a frontline service employee. The stronger the pressures, the greater the conflict created for the service employee (Kahn, Wolfe, Quinn, Snoek, \& Rosenthal, 1964). In terms of personalisation, the employee's conflict is between timely completion of tasks and the desire by customers for personalised encounters which may increase the level of pressure felt by the employee (Bettencourt \& Gwinner, 1996). These conflicting demands are amplified by the perceived inequality felt by service providers. The asymmetry of status and power between the provider and customer is such that conflict may become particularly prominent when inequality may not normally be present outside the organisation and/or runs counter to the self-image or esteem of the service provider (Papadopoulou-Bayliss, Ineson, \& Wilkie, 2001).

Few studies have explored the role conflict experienced by service providers when engaged in co-created service encounters with highly engaged customers. While there is evidence of a positive relationship between customer participation and service providers' perceived workload, few studies have considered the effects of increased collaboration on the psychological workload and role conflict of employees (Hsieh, Yen, \& Chin, 2004). Additionally, studies to date have mainly focussed on role conflict and ambiguity as experienced by front-line, boundary spanning employees (Chung \& Schneider, 2002; Shamir, 1980; Tang \& Chang, 2010). Employees who undertake more professional service roles (such as, in our case, professional archive, museum and heritage staff) are however not immune to role conflict. We suggest that this form of conflict will have less in common with unequal 
relations of conflict between organisational and client demands. We explore an alternative form of conflict associated with degrees of asymmetry in the knowledge present in professional service roles and customers engaged in collaborative service encounters.

\section{The Changing Landscape of Professional Heritage Practice}

Museums, archives and related heritage sites which anchor themselves in spatial and temporal terms may be perceived as "intermediaries and laboratories for experimenting with new cultural combinations and encounters" (Pieterse, 1997, p. 141). Unsurprisingly, reflexivity within the profession on the changing ethical requirements necessary to fulfil this has entered the mainstream discourse of curatorship and wider heritage practice (Bryce \& Carnegie, 2013; Chandler, 2009). However, hierarchies of patronage, trusteeship, variable extent of state funding and the pressure to commercialise act as external stimuli which places ancillary pressures on ideal notions of professional ethics in the heritage sector (Fyfe, 1995). Therefore, the heritage sector represents the convergence of national, religious or communities' values, those of practitioners charged with preserving and interpreting them to the public and the inclusion of commercial and political interests (Bennet, 1995; Foucault, 1989; Hammersley, 2000).

As Delafons (1997) states, enabling conservation, interpreting collections, sites and their relationship with the past and contemporary concerns is the primary role of professional heritage staff. Trotter (1998) adds that a de-centring of the assumed authority of the collecting or holding institution has allowed attentiveness to the provenance of objects, records and the ideas they impart to both scholars and lay visitors to develop. Both of these viewpoints are enclosed within the boundaries of institutional discourse, reflecting ethical debates within heritage practice itself. 
Wenger (2000) maintains that framing themselves as communities of cultural practice acts to embed the socio-cultural legitimacy of museums and other heritage sites. As such, staff are under pressure to adapt to these wider concerns, which do not touch on their core professional ethics in an intrinsic sense. These values, often underwriting the integrity of institutions' core appeal as repositories of favoured versions of the past and current values (Barr, 2005; Hetherington, 2000; Radakrishnan, 1994), are under pressure to be maintained. Yet these values cannot be other than reshaped by commercial and political pressures to modify their delivery to the citizen reformulated as consumer. Heritage sites, museums, archive centres and the buildings, landscapes, objects, and documents in their stewardship therefore become material, visual and textual, viewed from a variety of perspectives: professional, consumer and commercial (Claessen \& Howes, 2006). These perspectives may happily coalesce around mutually reinforcing curatorial ethics and the demands of the market and of consumers.

Tufts and Milne (1999) offer an account of the increasing pressure for museums to compete with private-sector attractions under what we will call the panoptical (Foucault, 1979, p. 197) gaze of the market. Garrod \& Fyall (2000, p. 703), however, note that many practitioners are resistant to commercial pressures as contrary to their fundamental professional mission. Apsotolakis (2003, pp. 808-809) later observed a consumer-orientation turn in heritage tourism management in which a change in curators' managerial ethos is required in order to incorporate the increasing significance of market operations and customer preference patterns. Chhabra (2008) argues curators and museum managers are subject to demands to generate diverse sources of revenue of which tourism is only one source. As a result, "the contemporary museum's role in the midst of a local community nexus is contingent upon local financial support of multiple audiences, it faces the threat of internalising multiple ideologies" (Chhabra, 2008, p. 35). 
Despite all these caveats, hierarchical assumptions about the curator-visitor relationship may linger across the sector, for sound professional reasons (O’Neill, 2012). The curatorial role is still widely understood to be the stewardship, organisation, presentation and interpretation of entire collections for an audience in total, not to provide bespoke services. Where does this top-down discourse leave consumers, who see themselves and the what, where and why of what they consume in contingent, often individual terms (Maoz \& Bekerman, 2010; Munt, 1994; Simmons, 2008)? Stylianou-Lambert (2011) registers complex, overlapping tourist motivations for heritage visitation, calling for greater attentiveness amongst researchers and practitioners to closely related forms of cultural consumption at home. Falk, Ballantyne, Packer, and Benckendorff (2012, p. 922) follow this line of thought in the personal relationship between travel and learning, calling for theoretical tools to develop "travel experiences that better fulfil the needs of visitors as well as the objectives of tourism providers". Lin, Morgan, and Coble (2013, p. 52) hint at more intimate relationships between tourist and heritage site when they discuss how the competing social construction of often abstract place-meanings demands recognition of the symbolic interactionism - selfperception and the awareness of how others define you - amongst visitor groups and as we will argue, amongst visitor groups and curatorial and archive staff.

This paper concerns itself with tourism as an important sector of heritage consumption and with the ancestral tourist market in particular. "Tourism needs destinations, and museums are premier attractions", often forming a network or locus for how the destination is conceived, represented and consumed in heritage terms (Kirshenblatt-Gimblett, 1998, p. 132). Indeed, the contextual data in this paper concerning ancestral tourists indicates the receptivity of professional staff to the active participation of consumers in co-creating heritage experiences as informed participants. In other cases the professional ethics of heritage providers may 
struggle to reconcile with consumers' sense of identity developed independently of curatorially legitimated discourse. Therefore, sites, institutions and collections may act in a traditionally understood hierarchical sense to embed consumers in empirically verifiable and academically legitimated relation to approved narratives (Jordanova, 1989). This appears to be particularly the case in the ancestral market where heritage consumers may have built up knowledge of 'lost homelands' through traditional cultural practice over centuries in various Diasporas; often in a manner quite distinct from how the nation is produced 'at home' (see Basu, 2004; 2005). As mentioned above, the meaning of texts and objects may be decontextualized due to the historical distance of visitors from particular events and, importantly, the commodifying effects of international tourism and other spheres of popular culture (Pollock \& Sharp, 2007).

\section{Methodology}

The overall aim of this study was to explore the relationship between changing professional discourse in the cultural heritage sector and role conflict amongst staff. Given the participatory consumption evident within ancestral tourism this was chosen as the focus of this study. The context for this setting was Scotland, given its long history of emigration and active Diasporas eager to return and visit the 'homeland' in increasing numbers (Devine, 2011; Visit Scotland, 2013). An analysis of trade publications (e.g. Tourism Intelligence Scotland, 2013), websites, and social media allowed the researchers to identify organisations that had an ancestral focus, for example: holding historical documents or artefacts; providing consulations to ancestral visitors; possessing detailed knowledge of local historical sites. As such, judgement was used in determining the sample. 
Archivists, museum curators, managers, and volunteers - all responsible for delivery of ancestral tourism within these Scottish sites - were approached via email to participate in the research project. While these roles are not necessarily focused on tourism (e.g. archives are not generally construed as tourist destinations), many employees within this context come in contact with visitors to the region as they search for information regarding their ancestors. A total of 31 interviews were conducted across 27 museums, heritage centres and family societies (see table 1).

Table 1. Sample characteristics

\begin{tabular}{|c|c|c|c|}
\hline Organisation & Attraction type & Gender & Role \\
\hline Applecross Heritage Centre & Local museum/ Heritage centre & Male & Curator \\
\hline Clan Donald Centre & Family History Society & Female & $\begin{array}{l}\text { Curator/ } \\
\text { Archivist }\end{array}$ \\
\hline Clan Macpherson Museum & Family History Society & Male & Trustee \\
\hline Culloden Battlefield & Historic Site/Place of Interest & Female & Manager \\
\hline $\begin{array}{l}\text { Dumfries and Galloway Family } \\
\text { History Society }\end{array}$ & Family History Society & Female & Volunteer \\
\hline Dunbeath Heritage Centre & Local museum/ Heritage centre & Female & Curator \\
\hline Elgin Cathedral & Historic Site/Place of Interest & Female & Curator \\
\hline Gairloch Heritage Museum & Local museum/ Heritage centre & Female & Volunteer \\
\hline Gairloch Heritage Museum & Local museum/ Heritage centre & Female & Curator \\
\hline $\begin{array}{l}\text { Glasgow Museums Resource } \\
\text { Centre }\end{array}$ & Archive & Male & Archivist \\
\hline $\begin{array}{l}\text { Grantown Museum and Heritage } \\
\text { Centre }\end{array}$ & Local museum/ Heritage centre & Female & Curator \\
\hline Hawick Heritage Hub & Archive & Female & Curator \\
\hline Highland Archive & Archive & Male & Archivist \\
\hline Highland Folk Museum & Historic Site/Place of Interest & Female & Curator \\
\hline $\begin{array}{l}\text { Kelvingrove Art Gallery and } \\
\text { Museum }\end{array}$ & National museum & Male & Curator \\
\hline Liddesdale Heritage Centre & Local museum/ Heritage centre & Female & Volunteer \\
\hline Lochaber Archive & Archive & Male & Archivist \\
\hline Mallaig Heritage Centre & Local museum/ Heritage centre & Male & Curator \\
\hline Nairn Museum & Local museum/ Heritage centre & Male & Volunteer \\
\hline National Museum of Rural Life & National museum & Female & Curator \\
\hline National Museum of Rural Life & National museum & Female & Marketing \\
\hline National Museum of Scotland & National museum & Male & Curator \\
\hline Riverside Museum & National museum & Male & Manager \\
\hline Seallam! Centre, Isle of Harris & Local museum/ Heritage centre & Male & Curator \\
\hline Skye Museum of Island Life & Historic Site/Place of Interest & Male & Curator \\
\hline Strathnaver Museum & Local museum/ Heritage centre & Female & Manager \\
\hline
\end{tabular}




\begin{tabular}{|l|l|l|l|}
\hline Strathnaver Museum & Local museum/ Heritage centre & Female & Volunteer \\
\hline Tarbat Discovery Centre & Local museum/ Heritage centre & Female & Manager \\
\hline Timespan - Helmsdale & Local museum/ Heritage centre & Female & Archivist \\
\hline Anonymity requested & Archive & Female & Archivist \\
\hline Anonymity requested & Archive & Female & Archivist \\
\hline
\end{tabular}

Interviews were conducted in person at locations throughout Scotland (see table 1). A broad range of sites across a diverse range of locations were considered to explore this context across the country. It was also deemed appropriate to explore a number of Scottish regions given the diverse historical and socio-cultural events which precipitated mass-emigration. For example, economic migration or the Highland Clearances which led to growing Diasporas across the world.

A semi-structured interview protocol was developed considering a range of aspects related to the visitor experience (see table 2). The purpose of the questions was to explore stakeholders' current interaction with ancestral tourists, as well as to understand any resourcing challenges associated with provision for such a market, particularly within smaller heritage attractions that do not always cater to the individual. Participants were asked to outline demographics and psychographics associated with ancestral tourism, before discussing the experience visitors have during their visit. Throughout the interview, participants were asked to give examples of the encounters they have had with ancestral tourists, the outcomes for the visitors' experiences, and implications for their role. Interviews lasted between 30 and 60 minutes and were digitally recorded before being transcribed verbatim. This enabled the researchers to explore aspects outlined by the participants which may not have been considered within the protocol. 
Table 2. Interview outline.

\begin{tabular}{|l|cl|}
\hline $\begin{array}{l}\text { Interview } \\
\text { component }\end{array}$ & Examples of questions \\
\hline $\begin{array}{l}\text { The ancestral } \\
\text { tourism market }\end{array}$ & $\begin{array}{l}\text { Are you aware of any specific differences between ancestral } \\
\text { tourists and tourists in general? }\end{array}$ \\
& $\begin{array}{l}\text { What are your experiences of working with ancestral tourists? } \\
\text { - }\end{array}$ \\
& $\begin{array}{l}\text { What reaction do you normally get from someone when you give } \\
\text { them news about their family history? }\end{array}$ \\
& $\begin{array}{l}\text { Have they ever been happy/ disappointed by what you have told } \\
\text { them? }\end{array}$ \\
\hline $\begin{array}{l}\text { The ancestral } \\
\text { tourist visit/ } \\
\text { Resources }\end{array}$ & $\begin{array}{l}\text { Do ancestral tourists ever contact you before they visit? } \\
\text { - }\end{array}$ \\
$\begin{array}{l}\text { What facilities/support do you provide that is specific to ancestral } \\
\text { tourists during their visit? }\end{array}$ \\
\hline $\begin{array}{l}\text { Impact and } \\
\text { ongoing }\end{array}$ & $\begin{array}{l}\text { Are there any specific challenges you face when dealing with } \\
\text { ancestral tourists? }\end{array}$ \\
\hline
\end{tabular}

Themes were identified inductively, with consideration of our dual themes of role conflict and curatorial ethics as overarching conceptual anchors. NVivo 10.0 was utilised as a tool for analysis, and researchers explored the themes, initially individually (Strauss and Corbin 1998). After this initial stage the research team met to agree upon a coding strategy, and four key themes related to both role conflict and curatorial ethics were considered: limited customer resource conflict; extensive customer resource conflict; limited customer and provider resource conflict; and, complex negotiation conflict.

\section{Findings}

Analysis of our findings identified role conflict as evident in the encounters which were revealed to us by our participants. However, those conflicts identified do not necessarily fit within extant understanding. In particular, conflict was associated with the relative presence or absence of customer and provider resources respectively. In this paper we consider these resources as operant and, in line with service-dominant logic, include knowledge and specialised competences (Lusch \& Vargo, 2014). Providers of ancestral services found 
themselves dealing with customers who have, generally, invested considerable emotional energy with the notion of 'being Scottish' and arrive with high expectations of discovering information about their ancestors. Therefore, for providers conflict was associated with both the expectations of the visitors versus the 'reality' of historical fact and/or the veracity of the information brought by visitors. We identify four distinct types of encounters from our data which relate to: limited and extensive customer resources, limited provider resources and finally complex negotiations. Each of these themes are now discussed in further detail.

\section{Limited customer resource conflict}

The first two themes centre on the extent of prior research/knowledge held by the visitor and its effect on the ancestral encounter. In some circumstances, visitors have arrived as part of a tour, and/or with limited information about their past. As a result, travel decisions have been made with a lack of detailed prior knowledge of their ancestry but, nonetheless, a strong desire to be considered part of a particular Scottish community or clan. For example, on Skye (a popular island destination for tourists), Clan Donald archivist Maggie often encounters tourists who have made the trip to Skye and invested in the notion of being attached to the Clan Donald: "they have made this trip across the Atlantic and they have picked this tour that comes to Skye because that is where their ancestors come from, but they don't!'. Maggie was left "feeling slightly guilty" when telling someone who had travelled so far that the information they believe to be correct is actually false. The lack of prior planning and research, in this case, creates role conflict on the part of the provider as they attempt to balance their curatorial role as custodian of historical 'truth' whilst simultaneously attempting to reduce disappointment in the visitor. This kind of encounter where visitors come with a fixed notion of belonging, yet lacking any evidence, was relatively common in our study: 
"Some people are very romantic and have fixated upon Applecross in particular with actually no real connection here. You have people turning up very certain that their ancestors were from Applecross but when you actually try to tease apart the information they have it very quickly becomes apparent that there is no tangible connection or no evidence that ever links their family here" (Gordon, Applecross Heritage Centre).

Gordon emphasises the lack of resources brought by ancestral tourists that have travelled so far yet still expect that proof will be provided at the site, reinforcing the conflict experienced by the provider associated with limited customer resources. In these encounters an asymmetry of resources is present in the traditional sense (the provider knows more than the consumer (Akerlof, 1970)). Yet, in co-created encounters, such as those outlined by Edvardsson et al. (2011) the pressure is on the provider to offer the visitor some kind of satisfactory encounter, which is challenging when the visitor's information set is limited.

\section{Extensive customer resource conflict}

Contrastingly, the second theme explores the notion of expectation management regarding those visitors whom have conducted a much higher level of preliminary ancestral research. In some encounters visitors commission genealogical work from overseas and bring a strong, predetermined notion of their ancestry. Several participants reported similar experiences such as Linda's:

"they come up with reams of very professional looking documentation proving without doubt that they are descended from somebody really notable” (Linda, Dumfries Family History Centre). 
This makes it difficult for professionals to counter this with empirically grounded information to the contrary, even when the veracity of a document brought by a visitor, ostensibly connecting them to popular historical figures like King Robert the Bruce or the poet, Robert Burns, is dubious. The conflict here relates to the pressure brought to bear by the visitor versus the sense of stewardship towards documents, objects, places and the integrity of their interpretation, felt by heritage professionals. Yet, professionals do respect the fact that ancestral visitors have invested a great deal, both emotionally and financially, in the expectation of a fulfilling heritage "experience". For example:

"The thing about this is that when people are enthused like that and they really truly believe that they are descended from this person and it has given them a certain amount of satisfaction and enjoyment and they are roaming about Dumfries and the whole of Scotland looking into it. I would hate to dampen their enthusiasm, you know” (Sandy, Dumfries Family History Centre).

While some who visit these centres have ancestral links which, in fact, can be traced back to battles such as Culloden, this is rare. As such, some research conducted by amateurs, or provided by other third parties, accompanied by a desire to be linked to notable figures from the past can provide false hope for individuals. In this theme the conflict was again related to asymmetry of information but unlike the previous theme the resources brought to bear by both visitor and provider were incompatible leaving the provider to attempt a compromise. Some providers like Sandy (previous quote) recognised that satisfaction could be derived from a limited intervention. Other curators attempted to offer a historically verified account which often didn't yield a satisfactory outcome: 


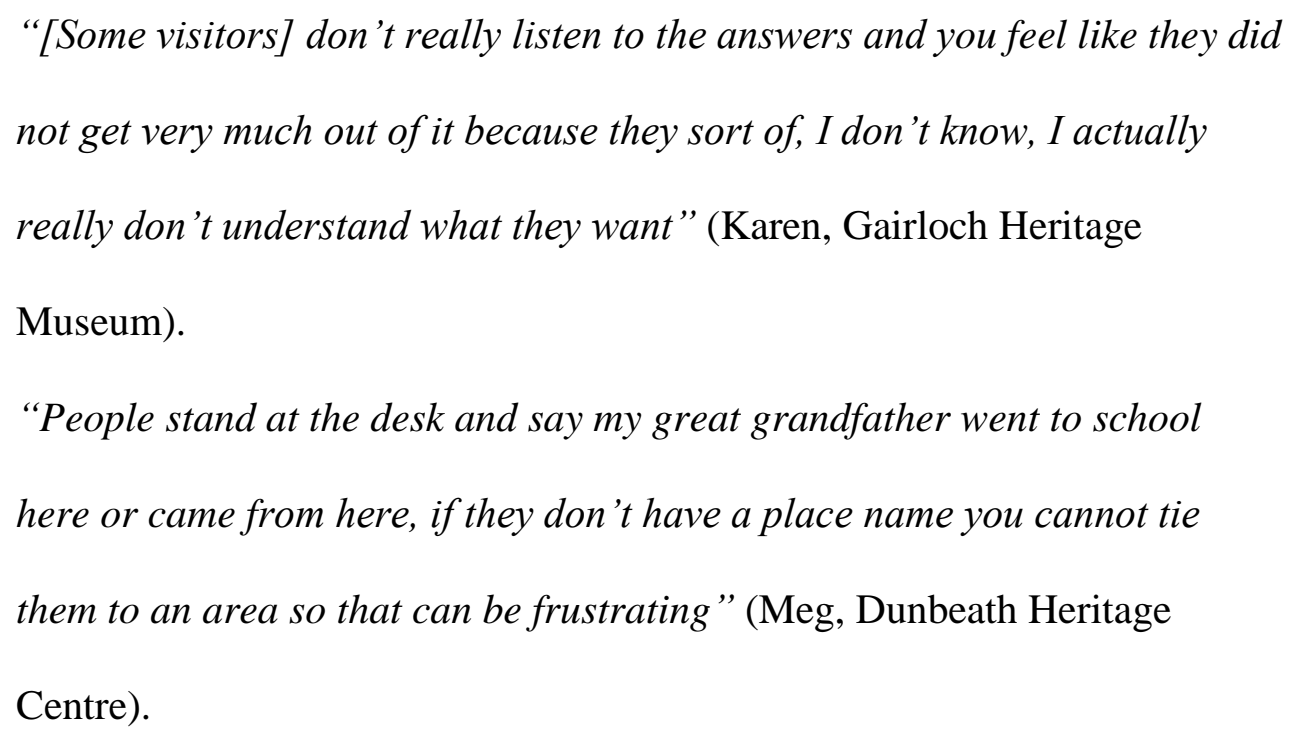

Balancing truth with visitor satisfaction is a difficult task to manage. Furthermore, it could be argued that the prevalence of visitors arriving with inflated hopes of ancestral ties could result in a lack of trust for future visitors' information presented to providers (Rizzo et al., 1970).

\section{Limited customer and provider resource conflict}

While limited customer assets are identified as a source of role conflict given customers' high expectations, another concern is the lack of resources available from a provider perspective. Not only do people arrive at heritage centres, museums, and archives with limited resources (specialist information and knowledge) themselves, they allocate little time for further research to be conducted. Without previously organising additional time at the organisations, it means that little can be done to assist them when providers are busy or when visitors arrive unannounced. For example:

"I have literally had that "I am a Grant and where was I [ancestor] from", it could be anywhere and so I feel a bit disappointed that sometimes I have not been able to 
devote more to these people, I feel their frustration" (Molly, Grantown Museum and Heritage Centre).

"[Visitors] come to you... about an hour before they have to leave for their flight and they are expecting to do their entire family history in that time is just often not possible even if they already have good starter information so we always try to do what we can and say that you can do this yourself online at home or we can do this for you but timing and expectation I would say would be key challenges" (Juline, Hawick Heritage Hub).

In these situations the conflict relates to the pressure brought to bear by the visitor versus the lack of resources (time) available to the provider. Another aspect of this conflict can be not only the lack of information from the customer, but the failure to use that information effectively. As Gordon discussed:

"What surprises me is the number of people who say, "my great grandfather came from here" and have travelled huge distances, come in with a scrap of knowledge but all their papers are at home... I have never been able to get my head around that somebody would spend five years researching their family tree and then come here but then leave everything back home and when you try to unpick what they are looking for you just cannot because they cannot remember anything and it is like oh I know he is a McRae which is the most common name here in the $19^{\text {th }}$ Century and it is just impossible to do anything, it is very frustrating" (Gordon, Applecross Heritage Centre). 
As such, the lack of information (as well as the abundance of a particular surname in a particular geographical site) results in incompatibility and asymmetry between visitor expectations and the resources providers are able to draw upon to support these. In situations such as these, professionals felt that while they only had a name or location to work with and may not be able to meet the expectations of the visitor, they were able to direct them to other resources as a substitute.

"they might be on that open top tour bus and the guide might point it out, oh we will go in there, they are coming in really unprepared, they have got no information and they will just say my name is such and such - well as vague as that - you will just say well we have books on that Clan or something and you can have a look at this book. If they have no information other than a surname" (Chris, Highland Archive).

“... so you would be able to point them in the direction of these particular places. The farmhouse, there may be no sign of any old black buildings left, maybe some rubble, but there are some very good books locally about the history of the place” (Ewan, Clan Macpherson).

As such, these practitioners have been able to accept the lack of personally specific resources, with which to work, yet draw upon more general information at their disposal to offer empirically grounded experience. This somehow 'softens the blow' for these visitors and appears to be aimed at ameliorating the experiences for consumers.

\section{Complex negotiation conflict}

The final theme relates to encounters where resources held by both visitors and providers were more or less symmetrical. Visitors' research was verifiable, and professionals at the 
location were able to assist them with their enquiries. However, this does not necessarily mean conflict is not evident in what seems like a perfect fit. In these cases providers could present the information to a customer, yet were placed in a delicate position given the nature of information they had found. For example:

"... the American who came and somebody was able to establish who his great uncle was and found that he had been executed in the electric chair in the States and they had to break the news to the family as to who this relative was so they said he was an expert in ... what was it, he was the chair of the Department of Electricity [laughs], oh I cannot remember it, but you have to occasionally say well this is the black sheep of your family and actually usually they are rather pleased" (John, Nairn Museum).

Another provider discussed a very delicate situation (specific details withheld), "it is an unhappy story... and there were people here who knew all about it and were too closely connected to the story”. The situation was resolved but it represented a considerable effort in diplomacy on the part of the provider involving professional, ethical judgement on whether or not to provide certain information.

"We were able to, we got her on the family tree but we did it in a way that we had almost not glossed over it, we had side-tracked her off what she was looking at ... but it is not that simple because there might be a criminal or there might be some iffy areas indeed in the past so there is always sensitivity, you will always have to be aware of the potential consequences of what you are telling people" (Identification withheld). 
The notion of consequences was highlighted by another participant who was confronted with a situation in which two customers presented a family tree at the museum with the same grandfather, within a week of each other, looking to explore their links without knowing that the other one existed:

\footnotetext{
"it is quite a shocking thing to find out what your ancestor had done - I mean life hasn't changed in that respect people were doing things then that they are still doing now but we know now and in those days you did not perhaps expect that and I was having to say that, you know your grandfather had other relationships and I thought they are interested enough and I made the decision that I should tell them and I did do and they went and got in touch" (Molly, Grantown Museum and Heritage Centre).
}

In this situation both visitor groups were very happy to be in contact with each other. However, the conflict experienced by Molly was evident given her custodianship of the situational knowledge:

"I felt like some kind of God making that decision to tell somebody... but I thought that it was meant to be, if I wasn't here they would never have probably found each other. They both came here trying to trace the same man who was their grandfather but they did not know that the other existed, it was quite extraordinary" (Molly, Grantown Museum and Heritage Centre).

These encounters, whilst in the minority compared with our other themes, nonetheless highlight the particularly emotionally heightened encounters heritage professionals in sectors like ancestral tourism can face and the resulting role conflict implications. 


\section{Discussion}

As indicated earlier, few studies have explored role conflict experienced by service providers when engaged in co-created service encounters with highly engaged customers. Our findings illustrate encounters by curators and other heritage professionals, resulting in varying types of role conflict associated with resource asymmetry. Given the individualised nature of ancestral tourism, and inflated expectations of consumers, this has led to co-created relationships where resources are asymmetric (Edvardsson et al., 2011). Conflict is experienced by providers who inform visitors that they may not in fact have any relation to an area or ancestor or, alternatively, that any information gathered is, to some extent, flawed. Visitors may have invested substantial time and money to travel to the destination to discover ancestral links and may not receive disconfirmation in an emotionally neutral sense. In line with Bettencourt and Gwinner (1996), pressure felt by heritage professionals was also related to the amount of time that was allocated by the visitor to find more personalised information about their ancestors, with many thinking a day is sufficient - contrary to the resources available to expert staff. As such, the level of operant resources offered by the visitor or available to the provider appears to play a significant role in the conflict felt by professionals providing an ancestral service to visitors.

Prior research in economics and marketing articulates notions of asymmetry between a buyer and seller (see Akerlof, 1970; Williamson, 1973). However, our research reveals nontraditional asymmetrical encounters in that neither party appears to be acting opportunistically to the detriment of others (Edvardsson et al., 2011). Ancestral encounters are asymmetric in the differing resource sets brought by each actor resulting in compromises made, usually by the provider, to ensure some kind of satisfactory outcome. 
This resource asymmetry results in role conflict when resource sets are more or less incompatible. Role conflict is typically associated with front line, subordinate, service roles and viewed as an outcome of incompatibility in situations where an employee is faced with conflicting demands from both organisation and customer (Schneider \& Bowen, 1985; Shamir, 1980). Our data, however, reveals conflicts particularly present in the ancestral tourism sector when individual demands for participation and access by the consumer and the knowledge, expertise and expert role of heritage professionals come into contact. Given the professional nature of many of our participants (curators, archivists and associated heritage professionals), this conflict represents a shift from those studies mainly focussed on subordinate service roles. Such situations are not as acutely felt in standard notions of the curator as provider and interpreter of knowledge-through-heritage in other spheres of cultural provision and consumption (Evans, 2014). However, despite the familiar boundaries of their professional role, the pressure on our participants to adapt to these individual encounters was genuinely felt, for example "Ifelt like some kind of God". Therefore, our research reinforces the suggestion that personalised encounters can increase pressure on employees and introduce additional complexity or conflict in more skilled professional and managerial roles (Bettencourt \& Gwinner, 1996).

Extant literature reports a number of usually negative potential outcomes for employees experiencing either role conflict or ambiguity (e.g. Boles et al., 2003) but there is also evidence that conflict sparks a more creative approach (e.g. Tang \& Chang, 2010). We reveal encounters where participants were forced to adapt their approach to heritage delivery due to the pressure brought by individuals seeking an individual experience. This adaptation appeared to take three principle forms: softening the blow; delivering bad news with a sugar coated pill, or; sticking to the facts. 
Firstly, some encounters required providers to soften the blow of negative outcomes. This kind of adaption was revealed in encounters where visitors with limited resource sets (but high levels of expectation) were not able to get confirmation of the ancestral past they perceived themselves to have. In these situations, professionals were placed in the uncomfortable position, from a strictly service-delivery standpoint, of disappointing a visitor. However, we found that some providers were unwilling to simply let a visitor leave on such terms. For example Molly at Grantown Museum and Heritage Centre, when faced with a 'Grant' descendant, but with no verifiable genealogical evidence, was able to direct visitors to places of interest which had more general, non-genealogical, associations with the Grant clan, thereby serving to ameliorate the disappointment for the visitor through the provision of a sense of "existential authenticity" (Steiner \& Reisinger, 2006). This suggests that the “symbolic interactionism” proposed by Lin, Morgan, and Coble (2013, p. 52) may translate into an active curatorial role, where the provider is able to intervene and salvage potentially unfulfilled consumer expectations through redirection to other empirically verifiable evidence of ancestry, albeit often of a less individual variety than that originally sought.

Our second form of adaptation also involved the symbolic interplay between ancestral visitor and providers delivering bad news with a sugar-coated pill where, in some delicate situations, providers would apply a mixture of professional and personal judgement. This involved offering visitors a version of the truth that allowing them to leave the site with some of their expectations ameliorated if not entirely fulfilled. Here we see curatorial ethical values being reshaped by commercial and political pressures, with delivery to consumers being modified accordingly. This included our account from Nairn where ancestors had been found guilty of a capital crimes or where they had been involved in a local scandal. In these cases the providers either provided selective pieces of evidence judged by them not to be 
potentially emotionally harmful to either visitors or community members with a stake in the issue, or simply to shift the visitors focus towards less problematic aspects of their family history.

The third form of adaptation was a desire to stick to the facts, whatever the outcome. This adaptation was least flexible and appeared to be most aligned with professional adherence to traditional modes of curatorial discourse where the institution serves as a repository of favoured versions of the past and current values (Barr, 2005; Hetherington, 2000; Radakrishnan, 1994). In our research, telling the truth (on the basis of historical evidence) would perhaps result in disappointment or, perhaps, the visitor resisting or choosing to ignore the evidence presented to them. This is perhaps evidence of many heritage professionals weighing up their core professional roles as stewards of documents and objects with the pressure to commercialise or personalise (Garrod \& Fyall, 2000) and coming to a purist, though entirely legitimate, decision on how to present ancestral heritage to visitors.

Our research adds to the variety of perspectives around curatorial and associated heritage roles where ethics and the demands of the market mean that pressures to adapt offerings according to consumer expectation may be in tension with established professional ethics of curators, archivists and associated heritage professionals (Classen \& Howes, 2006). Ancestral tourists have high expectations and often contribute extensive resources to encounters. These can often result in deeply emotional encounters and highly satisfied visitors. However, in this paper we focus on those encounters where, due to resource asymmetry, providers are faced with heightened levels of role conflict between the desire to satisfy visitors and the maintenance of curatorial ethics. We stress two final observations as signposts to our contribution to the wider and context-specific fields we have examined. Firstly, that role 
conflict in this context is not a product of the traditional hierarchical organisation where service employees interact with consumers according to the provision of a set of instructions, but rather a 'flattening' of consumer interaction with professional staff with an autonomous decision making role. Secondly, we note that role conflict in this case need not yield, as it has in much of the extant services literature, negative existential outcomes for employees. Rather, the particular dynamics of ancestral tourism as a subset of the cultural heritage market, often involves consumer expectations of interactivity and producer provision of useful resources. These can provide heritage professionals with rich, mutually beneficial encounters and the enhanced opportunity to intervene tactically to redirect consumer experience while maintaining their core ethical responsibility to the objects, documents and places in their care.

\section{Conclusion}

This paper offers insight into role conflict within the highly engaged and co-created context of ancestral tourism and proposes key contributions in relation to the challenges faced by service providers; more specifically, curators and other heritage professionals. The identified asymmetrical nature of resources within encounters can result in guilt from the providers' perspective as they have to inform visitors of the unfortunate lack (or differing nature) of information they are able to source, given restraints such as time, data availability, or misinformed consumers. Contrastingly, asymmetric resources can serve to heighten a sense of service disconfirmation from consumer perspectives given the resources they have expended to travel or research throughout the ancestral destination, and the inability of providers to give them the personalised information they seek.

Role conflict, while seen as a negative given, for example, reduced satisfaction of employees (Boles et al., 2003), has been proposed to also have a positive and direct impact on employee 
creativity. Further findings from this study show that creativity results in the adaptation of traditional approaches in three key ways: softening the blow; delivering bad news with a sugar coated pill, or; sticking to the facts. Thus, this contribution emphasises the creative nature of professional heritage staff when role conflict occurs, in highly engaged and collaborative roles with consumers.

\section{Managerial implications}

From the findings it has been possible to draw out several implications for service providers specifically within the ancestral tourism context, and further across hospitality and tourism. The identification of creative approaches used by service provides to adapt elements of role conflict act as a contribution in their own right. However, further implications can be pulled from these approaches by finding ways to reduce the asymmetrical nature of the relationship and make it more equitable. By providing consumers with an avenue to register their research in advance with heritage sites, this would enable information to be accessed by staff when the visitor arrives. However, education of the consumer would be essential, which would also assist in better developing expectations regarding the length of time it takes to search, or the expenditure of other resources. Softening the blow was an approach which enabled curators to strive for customer satisfaction while not necessarily being able to provide the level of detail hoped for by the visitor.

The understanding of role conflict within this sector also makes it possible for tourism organisations at national levels to better understand the stress and challenges faced by curators and heritage professionals who directly deal with any visitor seeking some form of personalised encounter. Thus, strategies to reduce this with, for example, enhanced links 
amongst heritage sites themselves and shared national capacity to interact with ancestral visitors in a range of domestic and overseas diaspora markets, would be beneficial.

\section{Future research and limitations}

The research undertaken explores role conflict from the specific perspective of heritage professionals. As such, levels of consumer satisfaction discussed within this study were subjectively determined by the providers interviewed. Future research may seek to understand the perspective of consumers of ancestral tourism in greater detail. Given the context under investigation, it would also be of benefit to explore the notion of role conflict in highly engaged heritage settings outwith the strict confines of ancestral tourism, and in a broader setting, than offered in this paper. 


\section{References}

Akerlof, G.A. (1970). The market for lemons: Quality uncertainty and the market mechanism. The quarterly journal of economics, 84(3), 488-500.

Apostolakis, A. (2003). Heritage tourism marketing. Annals of Tourism Research, 30(4), 795812.

Barr, J. (2005). Dumbing down intellectual culture. Museum and Society, 3, 98-114.

Basu, P. (2004). My Own Island Home: The Orkney Homecoming. Journal of Material Culture, 9(1), 27-42.

Basu, P. (2005). Roots tourism as return movement: semantics and the Scottish diaspora. In M. Harper (Ed.), Emigrant homecomings: the return movement of emigrants 16002000 (pp. 131-150). Manchester: Manchester University Press.

Bennett, T. (2005). Civic Laboratories: Museums, cultural objecthood and the governance of the social. Cultural Studies, 19(5), 521-47.

Bettencourt, L.A., \& Gwinner, K. (1996). Customization of the service experience: the role of the frontline employee. International Journal of Service Industry Management, 7(2), 3-20.

Boles, J.S., Wood, J.A., \& Johnson, J. (2003). Interrelationships of role conflict, role ambiguity, and work-family conflict with different facets of job satisfaction and the moderating effects of gender. Journal of Personal Selling \& Sales Management, 23(2), 99-113.

Bryce, D., \& Carnegie, E. (2013). Exhibiting the 'Orient': historicising theory and curatorial practice in UK museums and galleries. Environment and Planning A, 45(7), 17341752.

Chandler, L. (2009). Journey without maps': unsettling curatorship in cross-cultural contexts. Museum and Society, 7(2), 74-91.

Chhabra, D., Healy, R., \& Sills, E. (2003). Staged authenticity and heritage tourism. Annals of Tourism Research, 30(3), 702-719.

Chung, B.G., \& Schneider, B. (2002). Serving multiple masters: role conflict experienced by service employees. Journal of Services Marketing, 16(1), 70-87.

Claessen, C. \& Howes, D. (2006). The Museum as Sensescape: Western Sensibilities and Indigenous Artefacts. In E. Edwards, C. Gosden \& B. Philips (Eds.), Sensible Objects: Colonialism, Museums and Material Culture (pp. 199-122). Oxford: Berg.

Delafons, J. (1997). Politics and Preservation: a policy history of the built heritage 18821996. London: E \& FN Spon.

Devine, T. M. (2011). To the Ends of the Earth: Scotland's Global Diaspora, 1750-2010. London: Penguin UK.

Edvardsson, B., Tronvoll, B., \& Gruber, T. (2011). Expanding understanding of service exchange and value co-creation: a social construction approach. Journal of the Academy of Marketing Science, 39(2), 327-339.

Evans, C. (2014). The Impact of the Participatory, Visitor-Centered Model on Curatorial Practice. Journal of Museum Education, 39(2), 152-161.

Falk, J.H., Ballantyne, R., Packer, J., \& Benckendorff, P. (2012). Travel and learning: a neglected tourism research area. Annals of Tourism Research, 39(2), 908-927.

Fyfe, G. (1995) A Trojan Horse at the Tate: theorizing the museum as agency and structure. The Sociological Review. 43(1), 203-228.

Foucault, M. (1979). Discipline and Punish: the birth of the prison. London: Penguin.

Foucault, M. (1989). The Birth of the Clinic. London: Routledge.

Garrod, B. \& Fyall, A. (2000). Managing heritage tourism. Annals of Tourism Research, 27(3), 682-708. 
Guttentag, D. (2010). Virtual reality: applications and implications for tourism. Tourism Management, 31(5), 637-651.

Hammersley, M. (2000). Taking sides in social research. London: Routledge.

Heinonen, K., Strandvik, T., Mickelsson, K-J., Edvardsson, B., Sundström, E., \& Andersson, P. (2010). A customer-dominant logic of service. Journal of Service Management, 21(4), 531-548.

Hetherington, K. (2000). New Age Travellers: vanloads of uproarious humanity. London: Cassell.

House, R.J., \& Rizzo, J.R. (1972). Role conflict and ambiguity as critical variables in a model of organizational behavior. Organizational behavior and human performance, 7(3), 467-505.

Hsieh, A.T., Yen, C.H., \& Chin, K.C. (2004). Participative customers as partial employees and service provider workload. International Journal of Service Industry Management, 15(2), 187-199.

Jaakkola, E., \& Alexander, M. (2014). The Role of Customer Engagement Behavior in Value Co-Creation A Service System Perspective. Journal of Service Research, 17(3), 247261.

Jordanova, L. (1989). Objects of Knowledge: A Historical Perspective on Museums. In P. Vergo (Ed.), The New Museology. London: Reaktion Books.

Kahn, R.L., Wolfe, D.M., Quinn, R.P., Snoek, J.D., \& Rosenthal, R.A. (1964). Organizational stress: Studies in role conflict and ambiguity. New York: Wiley

Katz, D., \& Kahn, R.L. (1978). Organizations and the system concept. In J. Shafritz, J. Ott \& J. Yong. Classics of organization theory (pp. 161-172). USA: Cengage.

Kirshenblatt-Gimblett, B. (1998). Destination Culture: tourism, museums and heritage. Berkeley: University of California Press.

Lin, H-S., Morgan, M., \& Coble, T. (2013). Remember the Alamo: a cross-cultural analysis of visitor meanings. Journal of Travel Research, 52(1), 42-55.

Lusch, R.F., \& Vargo, S.L. (2014). Service-dominant logic: Premises, perspectives, possibilities. Cambridge: Cambridge University Press.

Maoz, D., \& Bekerman, Z. (2010). Searching for Jewish Answers in Indian Resorts: the postmodern traveler. Annals of Tourism Research, 37(2), 423-439.

Munt, I. (1994). The 'Other' Postmodern Tourism: culture, travel and the new middle classes. Theory, Culture \& Society, 11(3), 101-123.

O'Neill, P. (2012). The Culture of Curating and the Curating of Culture(s). Cambridge, MA: MIT Press.

Onyemah, V. (2008). Role Ambiguity, Role Conflict, and Performance: Empirical Evidence of an Inverted-U Relationship. Journal of Personal Selling \& Sales Management, 28(3), 299-313.

Papadopoulou-Bayliss, A., Ineson, E.M., \& Wilkie, D. (2001). Control and role conflict in food service providers. International Journal of Hospitality Management, 20(2), 187199.

Peñaloza, L., \& Venkatesh, A. (2006). Further evolving the new dominant logic of marketing: from services to the social construction of markets. Marketing theory, 6(3), 299-316.

Pieterse, J.N. (1997). Multiculturalism and Museums: Discourse about Others in the Age of Globalisation. Theory Culture Society, 14(4), 123-146.

Pollock, V., \& Sharp, J. (2007). Constellations of identity: place-ma(r)king beyond heritage. Environment and Planning D: Society and Space, 25(6), 1061-1078.

Poria, Y., Butler, R., \& Airey, D. (2003). The core of heritage tourism. Annals of Tourism Research, 30(1), 238-254. 
Radhakrishnan, R. (1994). Postmodernism and the Rest of the World. Organization, 1(2), 305-340.

Rizzo, J.R., House, R.J., \& Lirtzman, S.I. (1970). Role conflict and ambiguity in complex organizations. Administrative science quarterly, 15(2), 150-163.

Schneider, B., \& Bowen, D.E. (1985). Employee and customer perceptions of service in banks: Replication and extension. Journal of applied Psychology, 70(3), 423-433.

Shamir, B. (1980). Between service and servility: Role conflict in subordinate service roles. Human Relations, 33(10), 741-756.

Simmons, G. (2008). Marketing to postmodern consumers: introducing the internet chameleon. European Journal of Marketing, 42(3/4), 299-310.

Steiner, C., \& Reisinger, Y. (2006). Understanding existential authenticity. Annals of Tourism Research, 33(2), 299-318.

Strauss, A.L, \& Corbin, J.M. (1998). Basics of qualitative research: Techniques and procedures for developing grounded theory. Thousand Oaks, CA: Sage Publications, Inc.

Stylianou-Lambert, T. (2011). Gazing from home: cultural tourism and art museums. Annals of Tourism Research, 38(2), 403-421.

Tang, Y-T., \& Chang, C-H. (2010). Impact of role ambiguity and role conflict on employee creativity. African Journal of Business Management, 4(6), 869-881.

Timothy, D.J.,\& Boyd, S.W. (2006). Heritage tourism in the 21 st century: Valued traditions and new perspectives. Journal of heritage tourism, 1(1), 1-16.

Tourism Intelligence Scotland. (2013). Ancestral Tourism in Scotland. Retrieved from http://www.visitscotland.org/pdf/Ancestral\%20Research\%2016\%20Jan\%20vs.org_pp tx.pdf

Trotter, R. (1998). The Changing Face and Function of Museums. Media International Australia, Incorporating Culture \& Policy, 89(Nov), 47-61.

Tufts, S., \& Milne, S. (1999). Museums: a supply side perspective. Annals of Tourism Research, 26(3), 613-631.

Vargo, S.L., \& Lusch, R.F. (in press). Institutions and axioms: an extension and update of service-dominant logic. Journal of the Academy of Marketing Science. doi: $10.1007 / \mathrm{s} 11747-015-0456-3$

Visit Scotland. (2013). Summary of Ancestral Research 2012. Retrieved from: http://www.visitscotland.org/pdf/Ancestral\%20Research\%2016\%20Jan\%20vs.org_pp pp.pdf

Wenger, E. (2000). Communities of Practice and Social Learning Systems. Organization, 7(2), 225-246.

Wight, A. \& Lennon, J. (2007). Selective interpretation and eclectic human heritage in Lithuania. Tourism Management, 28(2), 519-529.

Williamson, O.E. (1973). Markets and hierarchies: some elementary considerations. The American economic review, 63(2), 316-325. 